\section{Instant zoogeography}

Aspects of Zoogeography. By Paul Müller. Pp. viii +208. (Junk: The Hague, 1974.) Dfl. 35.

Paul Mulifer is known for some interesting work on Brazilian reptiles and the zoogeography of South America. His latest work, entitled Aspects of Zoogeography, runs briefly through definitions of zoogeography and the biosphere. It summarises the characteristics of zoological realms, there are brief sections on each of nine terrestrial and two freshwater biomes. It contains a trendy little chapter on urban ecosystems. And the book ends briefly with historical aspects of zoogeography. All this in 170 pages, half of them occupied by illustrations.

It is difficult to see how some of the diagrams are related to the text and many of the diagrams are difficult to understand because they are too complex or the captions fail to describe them.

In the brief text, there is little discussion. For example, continental drift is mentioned but its relevance to animal distribution is not considered. The desert lizard Uromastix is listed as having salt glands but the significance of salt excretion for desert lizards is not discussed.

The book could be useful to a student

\section{BOOKS ON PURE AND APPLIED SCIENCE}

Books reviewed or mentioned in this journal are available from stock.

Catalogues on application.

Please state interests

\section{SCIENTIFIC LIBRARY}

ANNUAL SUBSCRIPTION from $£ 4.00$ Reduced rates for multiple subscriptions Available in U.K. only

Prospectus free on request

H. K. LEWIS \& Co. Ltd. LONDON: 136 GOWER STREET, WCIE 6BS

Telephone: $01-3874282$ who wants a synopsis of zoogeography. The references are there and the bibliography lists German works in addition to more familiar English and American works.

But the book is unsatisfactory because there is no assessment of the facts; and no personal opinion emerges, except for the assertion that the dispersal centre concept of Reinig and de Lattin should be given more attention. But it would be necessary to turn to de Lattin's work to discover the implications of that.

The book has been incompetently edited. There is no excuse for so many misprints.

Wilma George

\section{Colour and function of pigments}

The Significance of Zoochromes. By A. E. Needham. Pp. $x x+429$. (Springer: Berlin and New York, 1974.) \$26.50.

THE pioneer investigations of natural pigments by C. A. MacMunn at the end of the last century did not stimulate much interest among his contemporaries, and it is only within the last 25 years or so that his work has received the attention it deserves. Even now, however, researchers who have their main interest in pigments in their own right form a small and exclusive band.

Dr Needham's book is doubly welcome, for it not only considers animal pigments from the points of view of structure and function, but it also presents information and concepts which have never been assembled in one volume before. A discussion of the molecular basis of colour and the chemistry of the natural pigments is followed by the main part of the book which deals with the functions of these pigments. Biochemical and physiological rôles are considered, leading to an assessment-supported by evidence from motabolic pathways, from evolution and from the genetic basis of pigment formation-of the significance of the pigments in animals.

The format of the book is very pleasing, with particularly high quality typeface and paper. It was a good idea to preface each chapter with a brief synopsis of its subject matter and to include a conclusion section at the end. There are many tables which collect data not easily found elsewhere: the discussion of the taxonomic distribution of pigments with its accompanying table is a good example. The chapters dealing with integumental pigments and camouflage and the biogenetic evidence for their significance are of great interest, and the final chapter, a general assessment, contains much that is controversial. The list of references is comprehensive and most useful.

Unfortunately, the book contains many errors and misguided attempts to change well-tried and familiar nomenclature, which will make it irritating to those who have spent many years in this field. The title itself is provoking - why not 'Animal Pigments'? 'pigment' is a much better word than the rather pompous 'chrome', which, in any case, suggests the metal. To use the word 'porphyran' for 'metalloporphyrin' is misleading (malgré Fearon), and suggests a false relationship with porphyrin. The words 'glycose' and 'alkanol' are based on false logic. Use of the word 'chromasome' to describe a pigment granule leads to a hopeless confusion, both written and spoken. There is a daunting list of quite superfluous abbreviations at the beginning of the book.

Straightforward errors are more serious, and space allows mention only of the very worst. The use of the word 'chloroporphyrin' when 'chlorocruoroporphyrin' is meant is an illustration of the way in which obstinate pedantry reaps its own reward. Svedberg divided inventebrate haemoglobins into erythrocruorins and chlorocruorins for excellent and sound reasons, and it is chlorocruorin which gives rise to chlorocruorohaem and chlorocruoroporphyrin. Chloroporphyrin is a tricarboxylic derivative of chlorophyll. Phthalocyanins do not contain indole nuclei but are tetrazaporphyrins in which the methene bridges are replaced by tertiary $N$ and the four pyrrol rings are condensed with benzene rings in their $\beta$-positions. Fossil porphyrins do not always lose their $\mathrm{COOH}$ groups. Solubility data, fluorescence, and the formulae for many porphyrins are often wrong. The important feature of the Soret band in the porphyrin absorption spectrum is that it is dependent upon the integrity of the macrocyclic ring (not "superring"').

There are many omissions of important material which one would expect to find in a book of this kind. They include Warburg's ideas about primitiveness and the formyl group; mention of the pigments of birds' eggshells; the photodynamic work of Meyer-Betz, Boyd and Gaffron with porphyrins and proteins; and discussion of the effects of substituent groups and metals on the porphyrin absorption spectrum.

The author has striven too hard to achieve absolute exactness, and this has led him into pedantry and often downright error. Even as it stands, however, the book is a valuable and unique contribution to the literature on pigments.

G. Y. Kennedy 